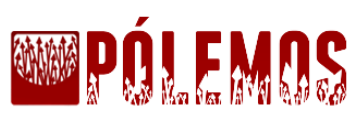

\section{SE HÁ UM EQUÍVOCO NO CETICISMO ATRIBUÍDO A HUME}

\section{Rafael Bittencourt Santos}

Resumo: Hume é comumente tido como um cético radical acerca do conhecimento causal. Isso porque Hume declara que as inferências causais não procedem de uma operação da razão, mas, antes, a partir do hábito e, assim, supostamente, seria irracional, segundo Hume, crer em raciocínios causais. Sugiro, aqui, que é improvável que Hume tenha assumido tal posição e, assim, que a atribuição de ceticismo a ele é inadequada, pois depende de uma concepção de conhecimento à qual Hume provavelmente não adere. Seu ceticismo dirige-se contra a metafísica, tal como entendida em sua época, porém perde a força contra a ciência empírica. Pretendo mostrar, para tanto, que na medida em que Hume considera o hábito como uma condição de possibilidade do conhecimento empírico, ele tem meios para superar o critério cético (entendido como a equipolência dos argumentos).

Palavras-chave: Hume, ceticismo, causalidade, conhecimento.

\begin{abstract}
Hume is usually reckoned a radical skeptic concerning causal knowledge. That is so because Hume claims that causal inferences do not rest upon the operations of reason, but rather upon habit. Some interpreters think we can conclude that for Hume it is irrational to belief in causal reasoning. I suggest here that it is unlikely that Hume supports such position, and, then, that such ascription of skepticism is inadequate, for it depends on a conception of knowledge which Hume probably does not accept. For this aim, I attempt to show that, as long as Hume views habit as a condition of possibility of empirical knowledge, he is able to coherently overcome the skeptic criterion (understood as the equipollence of arguments).
\end{abstract}

Keywords: Hume, skepticism, causality, knowledge.

\section{I - Introdução}

Hume é famoso por ter sido um dos expoentes modernos do ceticismo. Landesman, por exemplo, chama-o de "o cético mais radical da filosofia moderna" (LANDESMAN, 2002: 219). Por certo, o ceticismo é um aspecto relevante na filosofia de Hume, mas sugiro que seu ceticismo é bastante localizado e que, provavelmente, Hume não mereça o título de o cético mais radical da modernidade.

Neste texto, primeiramente, mostro como o critério do ceticismo - a equipolência dos argumentos - funciona para a denúncia da metafísica. Depois, mostro como Hume pretende evitar o ceticismo na ciência empírica e por que a sua saída não nos leva necessariamente à impossibilidade deste conhecimento. Uma das críticas que podem ser feitas à filosofia humeana é a de que, mesmo que ela se pretenda naturalista, não consegue superar o ceticismo que propõe. Isso, sustento, se deve a uma certa concepção de conhecimento, que não é unânime entre os epistemólogos atuais nem é provável que Hume a tenha adotado. 


\section{II - Considerações sobre a metafísica}

Tenhamos o discurso metafísico tradicional como aquele que pretende estabelecer verdades sobre a realidade a partir de princípios inquestionáveis ou infalíveis. Ainda, não são quaisquer verdades que o metafísico deseja alcançar, mas as verdades últimas, na ordem do conhecimento, ou primeiras, na ordem do ser. Tal caracterização é inspirada em Aristóteles. "Há uma ciência que investiga o ser enquanto ser" (ARISTÓTELES, 1908, p. 56). Tal ciência foi anteriormente caracterizada como aquela que deve "investigar os primeiros princípios e causas" (ARISTÓTELES, 1908, p. 5). Pode ser tomado de comum acordo que os filósofos medievais herdaram-na ${ }^{1}$.

Hume dividiu os objetos da razão humana em dois: aqueles cujas relações dependem inteiramente das ideias e aqueles cujas relações não dependem somente das ideias (T69). Essas relações são chamadas, por ele, respectivamente, de "relações de ideias" e "questões de fato ou existência", conforme as Investigações acerca do Entendimento Humano (E20²). Que $2+2=4$, por exemplo, seja uma proposição verdadeira depende apenas da relação entre essas quantidades e nada mais. Além disso, o contrário de tal relação $(2+2 \neq 4)$ é inconcebível. A verdade das relações concernentes às questões de fato, por outro lado, depende de algo exterior e independente das ideias relacionadas. A verdade da proposição "o meu exemplar do Tratado da Natureza Humana está debaixo do meu cubo mágico", por exemplo, não deriva somente da ideia que eu tenho do livro e do brinquedo, mas de como eles estão dispostos no mundo. Não é preciso mudar nada na concepção que tenho de ambos para que seja falso que eles estejam em tal relação, isto porque posso manter as ideias e a relação na mente e o estado de coisas no mundo não corresponder a elas (em contraposição com as verdades das relações entre ideias, o contrário das questões de fato é sempre concebível). De onde vem a certeza, então, que tenho de que meu cubo mágico está em cima do meu livro? Segundo Hume, não é de uma operação da razão ${ }^{3}$.

\footnotetext{
1 A metafísica irá ter, na modernidade, reformulações, como podemos ver em Kant e, mesmo, em Hume (esta é uma asserção que parte de uma perspectiva particular da sua obra, a qual não é o objeto no presente trabalho e, por isso, não será defendida). Uso "tradicional" justamente para referir-me às perspectivas mais antigas a de Hume.

2 Referências das Investigações acerca do Entendimento Humano iniciarão com "E" seguido do parágrafo correspondente na edição britânica.

Não entrarei nos detalhes de como Hume mostra (ou pretende mostrar) que a convicção no mundo externo não vem da razão, mas da imaginação. Basta, para os fins deste texto, que este seja um ponto pacífico na interpretação do filósofo. Monteiro (2003) levanta a hipótese de Hume ter quisto enriquecer o conceito de razão. Ainda assim, ele aceita que Hume negue a razão, tal como entendida na época (a saber, como razão dedutiva), seja a origem da convicção tanto no mundo externo como nas relações causais.
} 
Aqui já deve estar bastante claro o conflito com o discurso metafísico (tal como descrito acima). Se a mera operação da razão não nos garante a verdade das questões de fato, como é possível uma metafísica significativa? Afinal, a metafísica não pode apelar para a observação ou experiência, mas apenas para o raciocínio abstrato, puro. Se seguirmos Hume, teremos que concluir que os raciocínios metafísicos são totalmente incapazes de nos levar a adoção de um princípio em favor de outro ${ }^{4}$. O que podemos fazer são raciocínios hipotéticos, mas nunca alcançar a convicção.

Para ilustrar meu argumento, proponho olharmos mais acuradamente para a análise de Hume do princípio de que "tudo que começa a existir deve ter uma causa para sua existência" (T78-83) ${ }^{5}$. Tal princípio é caro às ciências, pois elas pretendem descobrir e predizer relações causais. E é a metafísica que se encarregaria de garanti-lo como verdadeiro a partir de princípios a priori. Além disso, muitos dos próprios raciocínios metafísicos precisam que tal relação seja garantida em um nível de "razão pura". Tomemos, por exemplo, a primeira das vias pelas quais Tomás de Aquino pretende ter demonstrado a existência de Deus. Que tudo que se mova precise ser movido por outro, ou que, para algo passar da potência ao ato é preciso que outro algo o faça, são apenas reformulações derivadas do princípio de que todo evento tem, necessariamente, uma causa.

Hume começa a sua exposição notando que tal princípio é tido como fundado na intuição. Se fosse fundado na intuição, deveria ser uma relação de ideias e, portanto, a priori. Além disso, as verdades resultantes de relações meramente entre ideias são tais que é impossível conceber a sua falsidade. Não podemos conceber, por exemplo, $2+2 \neq 4$. Podemos conceber que a nossa concepção esteja viciada, como propõe o argumento do Deus enganador de Descartes, porém é impossível conceber diretamente a falsidade de tal relação. Esse é um critério necessário porque estamos apelando apenas para as ideias, sem nenhuma interferência externa. Se nos é possível conceber A e $\neg$ A, isso significa que ambos podem ser derivados de nossas relações entre ideias. Sem poder apelar para nenhum outro recurso argumentativo que mostre a prevalência de um sobre o outro, só nos resta admitir que não podemos garantir a verdade de um ou de outro.

\footnotetext{
4 A não ser que admitamos uma metafísica que aceite raciocínios empíricos e que abra a porta, portanto, para raciocínios indutivos. Hume não parece negar totalmente a metafísica, apenas que ela passe ao largo da empiria. Em E132, ele aceita, por exemplo, que a Teologia possa ser fundada na experiência. A partir daí, teríamos que abrir uma discussão para saber se podemos chamar esse tipo de inquérito um inquérito legitimamente metafísico.

${ }^{5}$ Referências ao Tratado da Natureza Humana iniciarão com "T" seguido da página correspondente na edição britânica.
} 
É possível conceber X não existindo em t1 e existindo em t2 sem uma causa que o promova. O pulo para que digamos "a separação real desses objetos [a ideia de uma causa e a de um começo de existência] é possível” (T79, grifo meu) pode ser grande demais ${ }^{6}$, porém que é "impossível demonstrar a necessidade de uma causa" (idem) não o é. A necessidade, compreendida em termos metafísicos ("A" é verdadeiro em qualquer mundo possível), não é alcançada ao tentarmos provar o princípio de que todo evento tenha uma causa.

Hume analisa quatro tentativas de provar o princípio, a começar pela de Hobbes. Resumindo a exposição que Hume faz do argumento de Hobbes (T80), temos o seguinte:

a) Todos os pontos no espaço e no tempo onde supomos que um objeto pode passar a existir são equivalentes;

b) Se não há uma causa fixando o ponto, o objeto deve permanecer em suspenso (pois não há nada que o determine a existir no ponto 1, 2 ou qualquer outro).

Hume responderá tentando mostrar que o argumento não resolve o problema. Se é perfeitamente possível conceber a existência de um objeto sem a atribuição de uma causa, também o é sem lhe determinar uma causa para o quando e o onde virá a existir. A pergunta pelo se é anterior à pelo onde e quando.

Depois, Hume se dedica às tentativas de Clarke (T80-81) e Locke (T81). Ambas padecem do mesmo erro: pressupõem o que deve ser provado. O primeiro, em resumo, expõe o seguinte:

a) Se algo não tem uma causa, é causa de si mesmo;

b) Se é causa de si mesmo, existiu antes de ter existido;

c) Algo não pode existir antes de existir;

d) Portanto, é preciso lhe atribuir uma causa outra.

O segundo:

a) Se algo não tem uma causa, é causado pelo nada;

b) Do nada, nada vem (o nada não causa);

c) Não se pode ter o nada como causa;

d) Logo, é preciso que haja uma causa.

Como dito, ambas as tentativas pressupõem o que se quer provar. Hume argumenta que quando dizemos "X não tem causa" não estamos dizendo que "X é causa de si mesmo" ou que "o 'nada' cause X”, mas que X simplesmente não tem causa. Clarke e Locke já supõem

\footnotetext{
É discutível se tal critério é efetivo para a possibilidade, mesmo que lógico-metafísica, de um evento. Stroud (1977, p. 50) explora um contra-argumento bastante forte contra tal ideia. Contudo, como o intuito do texto não é, propriamente, mostrar a efetividade da filosofia de Hume, mas se a aceitando, deveríamos aceitar um ceticismo forte, não me demorarei neste ponto.
} 
a necessidade de uma causa e isso vicia as suas respostas, pois não consideram a alternativa (sem causa) que é proposta por quem desafia o princípio de que tudo tenha uma causa.

A última proposta de demonstrar o princípio de que tudo tem uma causa (T82) parte da premissa de que "todo efeito tem uma causa" e conclui que "uma causa é sempre necessária". Todavia, tal argumento faz uma generalização indevida ou confunde conjunto e subconjunto. O contra-argumento de Hume é dizer que do fato de que todo marido tem uma esposa não se segue que todo homem seja casado. Ora, de que todo efeito tenha uma causa não se segue que todo evento tenha uma causa. Aliás, o que se quer demonstrar é que todo evento é um efeito (de outro evento).

Tal é a argumentação de Hume contra a possibilidade de demonstrar a verdade do princípio de que uma causa é sempre necessária apenas a partir de relações entre ideias. É plausível a concepção do contrário e não há como mostrar, sem apelar para algo exterior às relações, que devamos preferir o primeiro. Esse pode ser tido como um exemplo paradigmático da incapacidade da metafísica, tal como entendida por Hume, de fazer um discurso que obtenha verdades sobre a realidade sem o apelo a nada mais que as relações entre ideias. O cético irá dizer que há argumentos plausíveis e igualmente fortes para defender tanto a necessidade de causas como a sua contingência, e que, por isso, não pode se decidir entre os dois.

\section{III - O método experimental}

Tal ceticismo mantém-se no nível metafísico (isto é, com relação às proposições metafísicas), tal como expus, pois este desconsidera a experiência ${ }^{7}$. Como visto, as relações entre ideias nas questões de fato dependem de algo extrínseco à relação das próprias ideias, o que a metafísica, por não considerar a observação, não poderia alcançar. Considerando, entretanto, a experiência, poderíamos fazer um discurso com propriedade sobre as questões de fato, ou, mais especificamente, ciência empírica?

O primeiro problema originado pelo apelo à experiência é a sua insuficiência para fazer demonstrações. O erro sempre é possível, e isto não por uma falha do homem (se considerarmos o erro humano, nem demonstrações são isentas de erro, uma vez que quem as

\footnotetext{
7 É importante ressaltar, novamente, que tal concepção de metafísica é específica à tradicionalmente tida pelos predecessores (e mesmo pelos contemporâneos a) de Hume. É possível ver ambições metafísicas no trabalho de Hume se houver a abertura para os raciocínios experimentais dentro do âmbito da metafísica. Ele, como já foi expresso em uma nota anterior, considera a Teologia, por exemplo, como podendo ter bases experimentais.
} 
faz e valida é o homem), mas pela própria natureza da investigação. É impossível o acesso a todos os casos possíveis - os que aconteceram, estão acontecendo e acontecerão, além dos que poderiam ter acontecido. Contudo, não é este o problema encontrado na filosofia de Hume. Podemos desconsiderar tal questão, não porque é irrelevante (pelo contrário, é de todo importante para a filosofia da ciência e teoria do conhecimento), mas porque não é ela que será levada em conta na atribuição de ceticismo a Hume. Nós - as pessoas em geral aceitamos a ciência como um empreendimento legítimo, ainda que tal problema exista. A falibilidade da experiência não é suficiente para dizer de Hume que ele é um cético, ainda mais um cético radical.

Sobre isso, poderia haver uma objeção bastante plausível. Se conhecimento, para Hume, só pudesse ser atribuído àquilo que é absolutamente certo, ou seja, a justificação deve garantir com certeza a proposição em questão, então a experiência é insuficiente para a produção de conhecimento e, assim, de ciência empírica. De fato, Hume não credita às questões de fato a possibilidade de conhecimento nesta acepção. Este só poderia ser atingido pelas relações entre ideias, pois são, segundo Hume, as únicas que podem nos dar certeza. Todavia, isso, por si só, é insuficiente para atribuir ceticismo quanto às questões de fato a Hume. Ele aceita que haja ciência empírica em sentido próprio. Como o faz, se a base dela é a experiência?

Há uma assimetria entre o que denominamos, no senso comum, conhecimento e o que Hume denomina conhecimento. Ele divide os argumentos em três: demonstrações, provas e probabilidades (E56 - nota 10). O primeiro seria fonte de conhecimento propriamente dito. "Provas" são aqueles argumentos fundados na experiência que produzem certeza. Proposições como “o Sol nascerá amanhã” ou "se eu jogar uma pedra para cima, ela irá cair", apesar de fundadas na experiência, parecem difíceis de serem duvidadas. Isto, na verdade, é uma “concessão" à linguagem comum. Parece, para o filósofo, um tanto quanto forçado dizer que tais proposições são apenas prováveis. Ele define como prováveis aqueles argumentos que têm experiências passadas contrárias e são, portanto, mais plausíveis de serem duvidadas. Nem sempre, por exemplo, o ópio faz dormir, embora o faça no mais das vezes.

Sobre isso, é interessante dizer que alguns cientistas, atualmente, fazem uma concessão quanto ao caráter de seu conhecimento. Eles aceitam que podemos falar que é provável, dada a evidência disponível, que a gravidade continuará atuando daqui cinco minutos. O que acontece é que, dada toda a observação de casos, mesmo que começássemos a escrever zeros após a vírgula no princípio do Universo, ainda não teríamos terminado de 
escrevê-los para determinar a pequena probabilidade disso não acontecer. Podemos ser inflexíveis ao ponto de dizer que uma justificativa que garanta 99,9999999999999999...\% da verdade não é suficiente para a atribuição de conhecimento, mas temos que aceitar que isso é mais que suficiente como motivo para crer. Ainda, não apenas que o sujeito está justificado no âmbito prático, mas também no teórico.

De qualquer forma, isto serve para mostrar a assimetria entre nosso vocabulário e o vocabulário humeano. Nós falamos na possibilidade de conhecer a partir de probabilidades (bastante fortes) e aceitamos tal procedimento como científico. Para Hume, conhecimento e probabilidade são qualitativamente diferentes (T181). Disso se segue que nenhuma probabilidade, por mais alta que seja, pode ser dita "conhecimento". A despeito disso, o filósofo aceita provas e probabilidades como legítimas para formar uma ciência empírica. Ele claramente desenvolve a sua ciência do homem sobre tais argumentos e acredita que a filosofia natural também se desenvolve sobre estes ${ }^{8}$.

Descartado o problema (ou suposto problema) da impossibilidade de demonstrar a universalidade ou necessidade de uma crença sobre questões de fato a partir da observação, um segundo surge, e este é mais contundente. A experiência, segundo Hume, exerce sua influência através do hábito, não da razão. Isso significa dizer que a certeza provinda da experiência vem de uma operação não-racional. Para Stroud, a origem dada por Hume à crença nas relações de causa e efeito (base dos raciocínios das questões de fato ${ }^{9}$ ) compromete a validade ou legitimidade teórica de tais crenças ${ }^{10}$. "Teórica" porque fica claro que o mecanismo de produção de crenças tem por fim o domínio da ação. Qualquer que seja o ceticismo humeano, ele não se estende ao domínio da vida ativa. A pergunta que fica é se sua teoria das crenças garante a atividade teórica, que deve se distanciar de alguma maneira da prática. Qualquer que seja a postura filosófica tomada, é preciso admitir uma diferença entre as exigências do mundo quotidiano e do terreno teórico, seja ela de grau ou de qualidade.

\footnotetext{
$8 \quad$ A favor da tese que estou defendendo, há o uso mais flexível de "conhecimento" na Investigação acerca do Entendimento Humano. A argumentação de T181 desaparece e Hume fala sobre conhecimento a partir da experiência (conferir E132).

Em T74, Hume pretende ter mostrado como as relações de identidade e contiguidade só produzem crença a partir de uma relação causal. Não analisarei seu argumento, apenas alternarei, de modo livre, entre "questões de fato" e "relações causais", pois aquelas estão fundadas nestas.

Alguns trechos do artigo O ceticismo de Hume: instintos naturais e reflexão filosófica, de Stroud, exemplificam essa posição. "Seu [de Hume] exame da natureza da crença e do papel da razão na gênese das crenças mostrou que, mesmo quando é cuidadoso e cauteloso ao extremo, ele não terá mais razão para crer em qualquer conclusão particular do que para desacreditá-la." (STROUD, 2008, p.171). "De fato, é pior que isso. Hume não somente deixa de afirmar ou implicar a verdade dessas crenças fundamentais ao explicar sua origem, ele nega-a explicitamente." (STROUD, 2008, p.174). Ou seja, a gênese, a origem, das crenças compromete-as epistemicamente.
} 
Aquele que questiona a origem das crenças causais e afirma que, dada tal origem, as crenças causais não são válidas para fundar uma ciência, faz o seguinte raciocínio: "O hábito é um princípio não racional, portanto é irracional aceitar as crenças provindas do hábito (no âmbito teórico)". Contudo, tal passagem não é necessária. Ela depende de uma concepção específica do que é legítimo para dar origem ao conhecimento e não é certo (nem mesmo provável) que Hume a aceitaria.

A justificação de uma crença para que tenhamos conhecimento deve ser racional. Este é um ponto pacífico. Isso não significa, porém, que apenas operações da razão possam ser base para a justificação. Se tivermos um princípio outro que tenha um considerável sucesso em produzir crenças verdadeiras, não seria racional aceitá-lo? Apesar de a razão não poder justificar o mecanismo pelo qual o hábito funciona, mas apenas explicá-lo, poderia "aproválo" por causa do seu sucesso em originar crenças verdadeiras sobre questões de fato. Um princípio seria epistemicamente válido se levasse, no mais das vezes, à verdade. O que deveríamos fazer é um rastreio das crenças a que chegamos por meio desse princípio criador. Aqui, temos dois problemas.

As considerações de Stroud (2008) vão de encontro a essa hipótese (de que as crenças originadas através do hábito conduzam, no mais das vezes, à verdade). As crenças fundadas no hábito, segundo ele, não visam à verdade. Verdade e falsidade não são fatores relevantes para a formação de crenças a partir do hábito. Portanto, não há nenhuma razão para atribuir veracidade a uma crença causal. Tal conclusão seria bastante desconfortável para um cientista, pois o que se pretende com um empreendimento científico é a verdade. Descartá-la seria deixar a ciência, enquanto teoria, sem finalidade.

Se o hábito não produz crenças pela sua verdade ou falsidade e, ao mesmo tempo, não é um mecanismo aleatório, o que pode ser visto como "regulador" da sua ação? Uma resposta que poderíamos dar é a utilidade. A utilidade dá conta do sucesso prático do costume como produtor de crenças e não o relaciona com a verdade. Isso explicaria, por exemplo, algumas crenças que não diríamos justificadas e que são produzidas pelo costume. O preconceito, por exemplo, é fundado no hábito. Por preconceito, entendo uma generalização demasiadamente apressada e cujo conteúdo não é ou cuja justificação não seja suficiente para considerá-la verdadeira. Uma moça, após três relacionamentos mal-sucedidos, pode concluir que nenhum homem presta. Alguém, após comer um prato mal-feito, pode dizer que não gosta daquele tipo de comida. São crenças fundadas no costume e Hume aceitaria isso. Ele dedica uma seção inteira do Tratado da Natureza Humana à análise de "costumes não-filosóficos" (T106- 
117). Isso pode minar minha pretensão de que a razão possa assentir ao hábito e também leva a uma segunda crítica.

Fogelin (2009) argumenta que a existência de princípios que nos levam a conclusões equívocas que são fundados no costume produz uma crise na filosofia de Hume. No fim, o insucesso de Hume em garantir a sua ciência do homem (para Fogelin, a "crise cética" de Hume é destruidora de suas pretensões) é causado por essa inconsistência do seu princípio. Ora, o costume nos leva a certas conclusões interessantes, entretanto, também leva a tantas outras que são claramente falsas. A proposta de um "rastreio" fica bastante comprometida. Afinal, dado que uma estatística real das nossas crenças particulares é inviável, é preciso um argumento que indique a legitimidade ou não legitimidade teórica dessas crenças. É preciso que justifiquemos a previsão de mais de $50 \%$ de acertos, por exemplo. Coisas como o preconceito minam tal previsão.

Albieri (2005, p. 87) oferece um argumento que, acredito, pode responder em bloco as duas interpretações (as quais levam a um ceticismo de Hume quanto às questões de fato).

\footnotetext{
$\mathrm{Na}$ teoria do conhecimento de Hume, instintos naturais, enquanto princípios da natureza humana, atuam como condições de possibilidade da percepção e do conhecimento, como o aparato cognitivo que informa os modos de conhecer. A eles, enquanto pontos de partida ou condições de possibilidade, verdade e falsidade, erro e acerto não se aplicam. Acerca do solo de nossas percepções, como acerca de questões de fato e de existência, a razão é segunda em relação à natureza. E só no mundo dos objetos organizado pela crença ela pode atuar, agora sim metodizando e corrigindo constantemente nossas inferências, mas não o mecanismo natural de fazê-las. (grifos meus)
}

A inclusão do hábito não significa uma expulsão da razão e dos compromissos com a verdade, mas a própria possibilidade de alcançá-la. A razão, por si só, não é capaz de dar conta da realidade como ela nos aparece. Ela precisa do auxílio da experiência, que só influencia na medida em que o costume está em nós como instinto natural. É esse o aparato que o homem dispõe para conhecer o mundo. Os voos metafísicos são altos demais para a natureza humana, porém os voos de nível experimental, não.

A crítica de Stroud é parcialmente barrada na consideração de que não podemos deixar de aceitar aquilo que é condição para que percebamos e conheçamos o mundo. Ora, não pode ser considerado irracional aceitar aquilo que não se pode recusar. Não é razoável chamar o impossível de racional, pois o impossível não é uma alternativa existente. Se A é impossível, A está dentro daquilo que não deve ser considerado em nossos raciocínios. Só faz sentido dizer que algo é racional ou irracional quando envolve escolha, mas, no caso em questão, não há tal coisa como escolha. Não podemos escolher A. 
Pode ser dito que nada disso consegue defender a razão teórica. Talvez a saída mais plausível seja a de dar àquele que afirma que o impossível é racional o ônus da prova, no entanto esta não é uma saída muito interessante. O que pode ser dito é que Hume parece, em certo sentido, admitir um fracasso no âmbito puramente teórico e compensá-lo com a valorização do domínio prático, explorando uma concepção da investigação filosófica e científica próximas da ação ou do senso comum. Isto parece ser indicado mais claramente na seção I da Investigação acerca do Entendimento Humano. Explorar profundamente tal seção exigiria um texto a parte (e por isso não o farei aqui), mas uma citação indica essa valorização do âmbito prático. "Tolere sua paixão pela ciência, diz ela [a Natureza], mas deixe sua ciência ser humana, e que ela possa ter relação direta com a ação e a sociedade" (E4). Ou seja, abandone aqueles interesses puramente abstratos.

Todavia, é possível fazer um esforço, sem apelar para a concepção de filosofia de Hume, para superar este problema. Para evitar tal crítica e, também, a de Fogelin, é preciso reconhecer a fiabilidade do método indutivo. Podemos distinguir hábitos fiáveis de hábitos não fiáveis e é isso que Hume propõe. Hume, na seção Das Probabilidades Não Filosóficas (T143-155), identifica modos de raciocinar considerados ilegítimos em um inquérito filosófico ou científico. O que faz, desses raciocínios, raciocínios não apropriados para uma investigação é a presença de fatores alheios àquilo que está na ideia de causalidade. Hume, na seção II da parte III do livro I do Tratado da Natureza Humana, identificou três características das relações de causa e efeito, a saber, a contiguidade espaço-temporal entre a causa e o efeito (T75), a prioridade temporal da causa em relação ao efeito (T 76) e a conexão necessária entre a causa e o efeito (T77). Os raciocínios considerados não filosóficos são influenciados por forças que não têm relação alguma com tais características das relações causais, como, por exemplo, o efeito da distância temporal de um evento. "O argumento que fundamos sobre qualquer fato de que nos lembramos será mais ou menos convincente, conforme o fato seja recente ou remoto." (T143). Tal influência é rejeitada pela filosofia, no entanto tem força sobre a mente.

O raciocínio não filosófico mais relevante para o presente trabalho é aquele denominado, por Hume, "regras gerais". Hume afirma "Uma quarta espécie de probabilidade [não filosófica] é aquela derivada de regras gerais, que nós apressadamente formamos para nós mesmos [...]" (T146 - grifo do autor). Ou seja, ela (a probabilidade) é atingida após uma generalização demasiadamente apressada a respeito do que observamos. No entanto, o que é um problema para Hume, tal generalização se dá a partir do mesmo princípio de um 
raciocínio filosófico, a ação do hábito (T147). Frente a isso, a essa aparente inconsistência da imaginação, que nos leva, pelo mesmo princípio, a unir corretamente e incorretamente ideias, Hume propõe uma espécie de correção através da reflexão acerca da atuação do hábito. Ele atribui o erro à consideração, pela imaginação, de circunstâncias supérfluas, conjunções acidentais. E conclui "Podemos corrigir essa propensão [em considerar circunstâncias supérfluas] mediante uma reflexão sobre a natureza dessas circunstâncias; mas, ainda nesse caso, é certamente o costume que sai na frente, imprimindo a inclinação à imaginação" (T148). Ou seja, fazendo uma análise do que está influenciando a mente a fazer determinada associação, é possível identificar elementos espúrios e, assim, observar a falha de tal associação.

É factível e razoável que, dado os sucessos e insucessos das relações que fazemos, possamos propor regras para que certas relações sejam aceitas e outras não. Quando um cientista tenta diminuir ao máximo o número de variáveis, quando refaz os testes e pede a outros que também o refaçam, ele está tentando minimizar a possibilidade do erro e maximizar a possibilidade do acerto. Tais regras, portanto, servem como uma espécie de filtro para que conclusões errôneas e equivocadas não passem. Algumas, eventualmente, irão ser aprovadas pelo método, mas em número bem menos expressivo. Este modo de proceder, que tem uma inspiração falibilista, parece ser aprovado por Hume. "Seguir regras gerais é uma espécie de probabilidade muito pouco filosófica. Entretanto, apenas se as seguimos podemos corrigir a esta e a todas as outras probabilidades não filosóficas" (T150). Ou seja, Hume defende que devemos corrigir as falhas dos raciocínios não filosóficos através do seu uso, pois é usando-os que identificaremos seus erros.

Hume sinaliza essa conclusão um pouco antes nesta seção (Das probabilidades não filosóficas). "Mais adiante, observaremos algumas regras gerais pelas quais devemos regular o nosso juízo sobre causas e efeitos" (T149). E dedica uma pequena seção do Tratado da Natureza Humana para uma espécie de "lógica indutiva" (Regras para se julgar a partir de causas e efeitos, T173-176). Tal espaço é evidentemente pequeno demais para sistematizar um método expressivo que dê conta da nossa prática indutiva e, ainda, é possível questionar certas regras. Até que ponto, por exemplo, a regra I, segundo a qual a causa e o efeito devem ser contíguos no espaço e no tempo, pode ser aplicável à ação da gravidade? De qualquer forma, Hume sinaliza para tal saída, ainda que não a faça de modo suficientemente amplo para criar um método, o que não pode ser considerado uma falha, dado que seu objetivo era explicar o modo pelo qual julgamos a partir de causas e efeitos, não fazer um sistema. 
Antes de concluir, é interessante notar que podemos observar, na Investigação acerca do Entendimento Humano, uma compreensão falibilista da ciência do homem como um todo, não apenas com respeito ao método indutivo.

[...] não têm sido [os críticos, lógicos e filósofos políticos], em suas tentativas, totalmente malsucedidos. Talvez, com o passar do tempo, maior exatidão e aplicações mais zelosas possam levar essas ciências para ainda mais perto da sua perfeição. (E9)

A crítica, a lógica e a política são áreas da ciência do homem. Hume nota a existência de fracassos em tais ciências, no entanto, isso não o leva a abandoná-las.

\begin{abstract}
Abandonar de uma vez todas as pretensões deste gênero [de aperfeiçoar as ciências do homem] pode, de modo justo, ser considerado mais imprudente, precipitado e dogmático que a mais audaciosa e mais afirmativa filosofia que já tenha tentado impor suas doutrinas e seus princípios imperfeitos à humanidade. (E9)
\end{abstract}

Descartar a ciência do homem pelo fato do seu método ser imperfeito é, segundo Hume, uma atitude incorreta. $\mathrm{O}$ que deve ser feito, de acordo com ele, é desenvolvê-la de modo a aperfeiçoá-la. Parar na constatação do erro e da imperfeição é a atitude dogmática. A atitude filosófica nos leva adiante, ao aprimoramento do nosso método, não à sua mera negação. A partir da aceitação dos limites da natureza humana, empreender uma investigação dentro de tais limites.

\title{
IV-Ceticismo
}

Assim, é um equívoco de Fogelin a atribuição de um ceticismo "indutivo" ou "causal" a Hume. Este não desqualifica as atribuições de relações de causa e efeito, considerando-se as peculiaridades do seu sistema. Poderia ser dito, por exemplo, que a impossibilidade de justificar as crenças que temos em relações causais através de princípios dedutivos seria suficiente para desqualificar epistemicamente o seu uso legítimo em atividades teóricas (ciência e filosofia). Poderíamos ver como alternativa um método falsificacionista, no qual, supostamente, não teríamos dependência alguma de procedimentos indutivos. No entanto, uma discussão desse gênero foge aos propósitos deste texto, que tem o caráter de um comentário, e entraria em um terreno mais temático. O propósito deste artigo é mostrar que Hume não é um cético indutivo, não que ele está plenamente justificado em rejeitar tal ceticismo ou que sua filosofia é consistente.

Obviamente, a relação entre Hume e o ceticismo não se resume a isto. O ceticismo, na filosofia de Hume, tem uma função quase que terapêutica. $O$ cético radical não é um 
adversário que deve ser superado, mas alguém que nos lembra a humanidade do empreendimento filosófico e que não precisa ser respondido. Ele, na verdade, sequer existe. O cético moderado, por outro lado, existe e tem fortes argumentos, cujos efeitos atingem a metafísica tradicional. Para que a metafísica seja possível, é necessária uma remodelação do seu método, abandonando as velhas pretensões apriorísticas e abrigando a experiência. Hume, por fim, aceita, para a sua filosofia, o ceticismo moderado. O que isso representa, em um âmbito mais geral, é matéria para outro texto ${ }^{11}$.

\section{Referências Bibliográficas}

ALBIERI, Sara. "Crença e Aceitação: A Teoria Humeana da Crença como Conhecimento Confiável”. In: GUIMARÃES, Lívia. Ensaios Sobre Hume: II Colóquio Hume. Belo Horizonte: Segrac Editora e Gráfica Limitada, 2005, p. 79-88.

ARISTÓTELES. The Works of Aristotle, v. 3. Trad. J. A. Smith, W. D. Ross. Oxford: Clarendon Press, 1908.

FOGELIN, Robert. Hume's Skeptical Crisis. Oxford: Oxford University Press, 2009.

HUME, David. A Treatise of Human Nature: Being an Attempt to Introduce the Experimental Method of Reasoning into Moral Subjects. Ed. Selby-Bigge/P. H. Nidditch, Oxford: Clarendon Press, 1978.

Enquiry Concerning Human Understanding. Ed. Selby Bigge/P. H. Nidditch, Oxford: Clarendon Press, 1975.

LANDESMAN, Charles. Ceticismo. Trad. Cecília Camargo Bartalotti. São Paulo: Edições Loyola, 2002.

MONTEIRO, João Paulo. Novos Estudos Humeanos. Lisboa: Imprensa Nacional/Casa da Moeda, 2003.

STROUD, Barry. Hume. London: Routledge \& Kegan Paul, 1977

O Ceticismo de Hume: Instintos Naturais e Reflexão Filosófica. Trad. Plínio Junqueira Smith. Sképsis, São Paulo, vol. 4, n. 3, 2008. p. 169-192

\footnotetext{
${ }^{11}$ Além disso, o modo como Hume trata e divide o ceticismo em pirrônico (radical) e acadêmico (moderado), recusando aquele e aceitando este, também pertence a uma discussão mais geral e, por isso, não foi tratado aqui. Basta, para os propósitos do presente artigo, que compreendamos o cético radical como aquele que denuncia e considera como impossível o conhecimento, enquanto que o cético moderado corresponde à visão de Hume exposta ao longo do texto. Ele compreende os limites do homem, respeita-os e constrói o conhecimento dentro de tais limites.
} 